\title{
Scarabiasis: A rare infestation in humans
}

\author{
Dona Banerjee ${ }^{1},{ }^{*}$ Kallol Bose ${ }^{2}$, Sudip Saha ${ }^{3}$, Madhusmita Sengupta ${ }^{4}$
}

Sri Lanka Journal of Child Health, 2016; 45(4): 286-287

DOI: http://dx.doi.org/10.4038/sljch.v45i4.7977

(Key words: Scarabiasis, dung beetle)

\section{Introduction}

Scarabiasis is a condition where beetles temporarily infest the digestive tract and this disease is seen in children living in tropical countries but is rarely reported. We here report three cases of scarabiasis we came across in our hospital in a span of around 6 months (January 2014 to June 2014).

\section{Case report}

A 2 year old boy, a 3 year 6 month old girl and a 6 year old girl came from villages of 3 different districts of West Bengal with histories of passing live beetles per rectum. The beetles were black in colour and small in size (Figures 1 and 2).

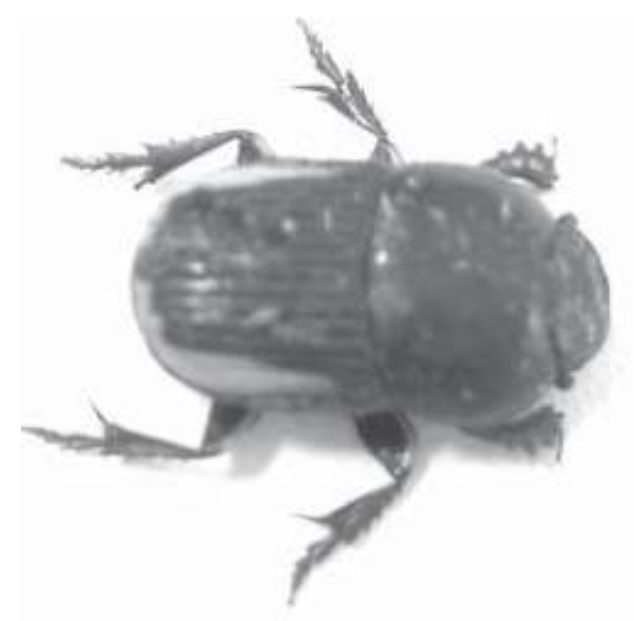

Figure 1: Dung beetle - Top view

\begin{abstract}
${ }^{1}$ Senior Resident, ${ }^{2}$ Assistant Professor, ${ }^{3}$ Associate Professor, ${ }^{4}$ Professor \& Head, Department of Paediatrics, Chittaranjan Seva Sadan \& Sishu Sadan, College of Obstetrics \& Gynaecology and Child Health, Kolkata, India

*Correspondence: subhosrisaha@gmail.com
\end{abstract}

(Received on 24 April 2015: Accepted after revision on 19 June 2015)

The authors declare that there are no conflicts of interest

Personal funding was used for the project.

Open Access Article published under the Creative

Commons Attribution CC-BY (c) (†)

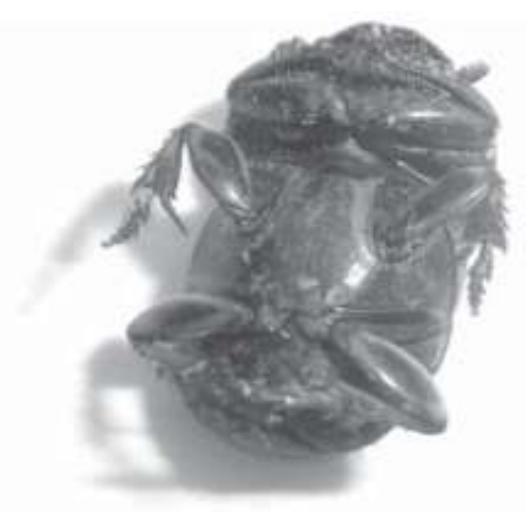

Figure 2: Dung beetle from below

The children had passed about 3 to 8 beetles during 2 to 3 episodes at an interval of 15 days, spread out over a 30 to 45 day period. All of them had poor appetite and mild periumbilical pain associated with occasional vomiting. They (except the boy) had no episodes of loose stools. There was no history of bleeding per rectum or mucorrhoea, faecal incontinence, faecal soiling, perianal ulcers or itch, abdominal distension, rash or wheeze and fever. They came to our institute after the parents were able to catch hold of one of the flies in order to support their history which was deemed unusual by their close associates. The families lived in small houses with cemented or mud floors and the children slept mostly on the floors. All of them were active children and often played without their underclothes in the adjoining playgrounds. In the neighbourhood, cows and cow dung were a common sight as their families or neighbours residing opposite their houses raised cattle for domestic purposes.

On examination, all of them were active, alert and playful, with mild pallor. There were no scratch marks, skin lesions or significant lymphadenopathy. The boy had a weight between 0 to $-1 \mathrm{Z}$-score and height of 0 to $-1 \mathrm{Z}$-score. The 3 year 6 month old girl had a weight in -1 to $-2 Z$ score and height in 0 to $-1 \mathrm{Z}$-score. The 6 year old girl had both weight and height between -1 to $-2 \mathrm{Z}$ scores. Their systemic examinations were normal. Perianal as well as rectal examinations were normal. Complete blood counts, erythrocyte sedimentation rate, stool examination for parasites and ultrasound of abdomen were essentially normal. With this history of passing probable dung 
beetles, a diagnosis of Scarabiasis was made. Beetles which were captured were sent to the 'School of Tropical Medicine, Kolkata, and identified as "Coprophagous beetles". All of them were given bowel cleansing with polyethylene glycol and oral metronidazole for 5 days and the parents were advised regarding sleeping habits, personal hygiene and wearing tight underclothes. They were doing well on follow-up.

\section{Discussion}

Dung beetles feed partly or exclusively on faeces and play a useful role in agriculture by burying and consuming dung, thereby improving the nutrient cycling and soil structure ${ }^{1}$. Temporary infestation of the digestive tract by dung beetles and 'flying away' from the anus at the time of the defaecation is termed Scarabiasis or Canthariasis ${ }^{1}$. In Scarabiasis, patients usually complain of loss of appetite, diarrhoea, cramps in abdomen and sometimes fever. Gradual emaciation is another significant feature ${ }^{2}$. There was no history of fever in our cases but one child had diarrhoea. All three children were undernourished.

Mode of entry of beetles in the human body is controversial, as to date no egg or larva has been found in the human stools ${ }^{3}$. One popular theory of scarabiasis is the entry of the larvae through the anus and its development in the large intestine into adult beetles which then fly out of the rectum ${ }^{3}$. However, some entomologists are of the opinion that faeco-oral transmission does occur in scarabiasis $^{4}$.

The suggested treatment of this atypical disease is simple and cheap ${ }^{5}$. Oral metronidazole, saline purgatives and polyethylene glycol help in killing the larvae and cleansing the bowel. Living at a distance from domestic animals and cow dung and wearing tight protective underclothes during sleep can prevent this rare disease. The 3 cases are being reported not only for its rarity but also to spread the awareness of this entity.

\section{References}

1. Brown J, Scholtz CH, Janeau JL, Grellier S, Podwojewski P. Dung beetles (Coleoptera: Scarabaeidae) can improve soil hydrological properties. Applied Soil Ecology 2010; 46:9-16.

http://dx.doi.org/10.1016/j.apsoil.2010.05. 010

2. Rajapakse S. Beetle marasmus. British Medical Journal 1981; 283:1316-7 http://dx.doi.org/10.1136/bmj.283.6302.13 16

PMid: 6794839 PMCid: PMC1507661

3. Majumder N, Datta SS. Scarabiasis in children: study from rural north-east India. Indian Journal of Medical Specialities Published online 27 February 2012

4. Hati AK. Beetles. Medical Entomology. Kolkata: Allied Book Agency; 1979. p. 93-6.

5. Karthikeyan G, Ganesh R, Sathiasekeran M. Scarabiasis. Indian Pediatrics 2008; 45: 697-9.

PMid: 18723917 